\title{
Effect of the interplay of composition and environmental humidity on the nanomechanical properties of hemp fibers
}

Raphaël Coste ${ }^{\dagger,, * \#, ~ M i g u e l ~ P e r n e s}{ }^{\dagger}$, Laurene Tetard $^{\#, \S}$, Michaël Molinari ${ }^{\ddagger}$, Brigitte Chabbert ${ }^{\dagger}$

† FARE Laboratory, INRAE, Université de Reims Champagne-Ardenne, 5110o, Reims, France

* Laboratoire de Recherche en Nanoscience (LRN) EA4682, Université de Reims Champagne Ardenne (URCA), France

\# NanoScience Technology Center, University of Central Florida, Orlando, Florida 32826, USA

§ Physics Department, University of Central Florida, Orlando, Florida 32816, USA

‡ CBMN UMR CNRS 5248, Université de Bordeaux, IPB, 3360o, Pessac, France

Number of pages: 3

Number of figures: 2

Number of tables: 2 
Evolution with time of the indentation modulus in the S2 layer of hemp xylem at $83 \% \mathrm{RH}$

As a delay is expected to observe the effective impact of the $\mathrm{RH}$ on the mechanical properties, the time required for stabilization was first determined by monitoring the indentation modulus over $24 \mathrm{~h}$ at $83 \% \mathrm{RH}$. At this $\mathrm{RH}$ the indentation modulus is expected to observe significant variations with respect to ambient conditions. Figure $\mathrm{S}_{1}$ displays the evolution of the indentation modulus of hemp xylem fiber in the S2 layer of the SCW region over a period of $24 \mathrm{~h}$ measured at right after the sample was set and then after $30 \mathrm{~min}, \mathrm{~h}, 2 \mathrm{~h}, 4 \mathrm{~h}, 8 \mathrm{~h}$ and $24 \mathrm{~h}$. The indentation modulus decreases significantly from $\sim 8.8 \pm 0.3 \mathrm{GPa}$ to $\sim 7.7 \pm 0.4 \mathrm{GPa}$ in the course of the first $4 \mathrm{~h}$. After $4 \mathrm{~h}$, the modulus did not observe any major change. As a result, a stabilization time of $4 \mathrm{~h}$ was adopted prior to all measurements with the environmental chamber.
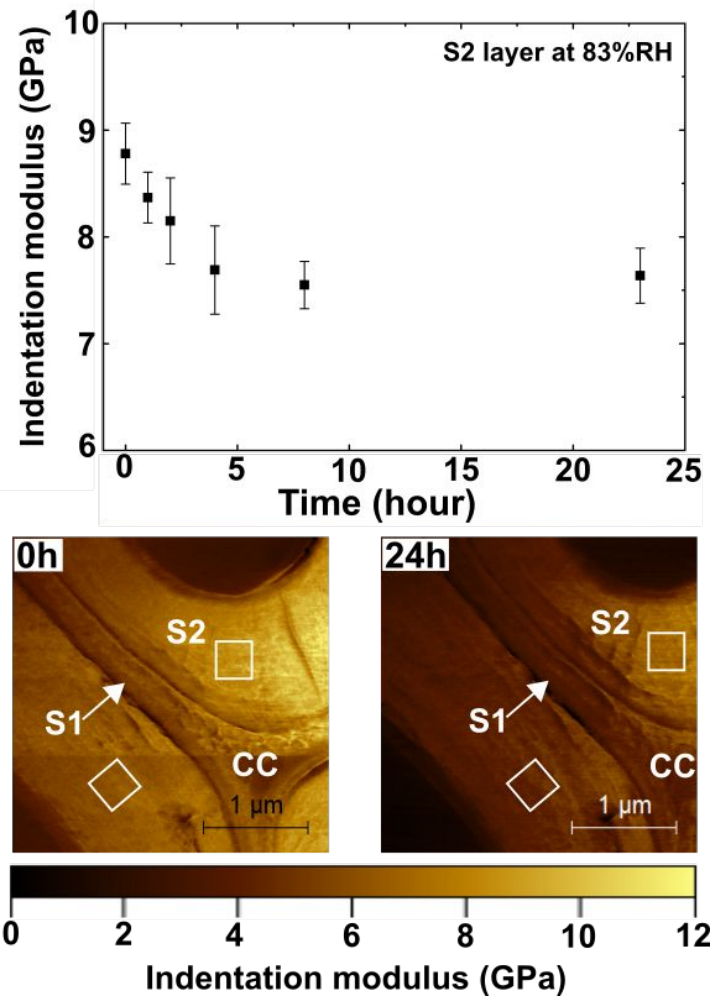

Figure S1. Evolution of the PF-QNM indentation modulus of hemp xylem fiber in the S2 layer over $24 \mathrm{~h}$ at $83 \%$ RH. (Bottom) maps of variations in indentation modulus across a region around the $\mathrm{CC}$ at oh and $24 \mathrm{~h}$. The white squares correspond to the regions where the force curves were acquired to form the graph (top). 


\section{Raman spectroscopy}

Tables S1 and S2 display the averages and standard deviations of the Raman intensity of three characteristic bands for both xylem and sclerenchyma fibers in the CC, CML and S2/G layers. The averages and standard deviations were calculated over 50 spectra for the CML, 200 spectra for the CC and 500 spectra for the $\mathrm{S}_{2} / \mathrm{G}$ layers.

Table S1. Averages and standard deviations of Raman intensity $\left(\mathrm{I}_{\text {Raman }}\right)$ of three characteristic bands in the xylem.

\begin{tabular}{|c|c|c|c|c|c|c|c|c|c|}
\hline \multicolumn{10}{|c|}{ Xylem } \\
\hline & \multicolumn{3}{|c|}{$\mathrm{CC}$} & \multicolumn{3}{|c|}{ CML } & \multicolumn{3}{|c|}{ SCW } \\
\hline & $\begin{array}{l}I_{\text {Raman at }} \text { at } \\
1330 \mathrm{~cm}^{-1}\end{array}$ & $\begin{array}{l}I_{\text {Raman }} \text { at } \\
1600 \mathrm{~cm}^{-1}\end{array}$ & $\begin{array}{l}I_{\text {Raman }} \text { at } \\
2937 \mathrm{~cm}^{-1}\end{array}$ & $\begin{array}{l}I_{\text {Raman }} \text { at } \\
1330 \mathrm{~cm}^{-1}\end{array}$ & $\begin{array}{l}\mathrm{I}_{\text {Raman }} \text { at } \\
1600 \mathrm{~cm}^{-1}\end{array}$ & $\begin{array}{l}I_{\text {Raman }} \text { at } \\
2937 \mathrm{~cm}^{-1}\end{array}$ & $\begin{array}{l}I_{\text {Raman }} \text { at } \\
380 \mathrm{~cm}^{-1}\end{array}$ & $\begin{array}{l}I_{\text {Raman }} \text { at } \\
1120 \mathrm{Cm}^{-1}\end{array}$ & $\begin{array}{l}I_{\text {Raman }} \text { at } \\
2897 \mathrm{~cm}^{-1}\end{array}$ \\
\hline $\begin{array}{l}\text { Average } \\
\pm \text { Std. dev. } \\
\text { (CCD cts) }\end{array}$ & $31.25 \pm 3.15$ & $62.21 \pm 8.43$ & $38.17 \pm 2.75$ & $19.98 \pm 2.53$ & $32.61 \pm 7.52$ & $39.25 \pm 1.49$ & $11.25 \pm 1.16$ & $13.88 \pm 0.99$ & $39.86 \pm 2.66$ \\
\hline
\end{tabular}

Table S2. Averages and standard deviations of Raman intensity of three characteristic bands in the sclerenchyma.

\begin{tabular}{|c|c|c|c|c|c|c|c|c|}
\hline \multicolumn{9}{|c|}{ Sclerenchyma } \\
\hline \\
\hline
\end{tabular}

\section{Atomic Force Microscopy}

Figure S2 shows 3 typical AFM force curves extracted from sclerenchyma G layer at 13\% RH, 43\% RH and 83\% RH.
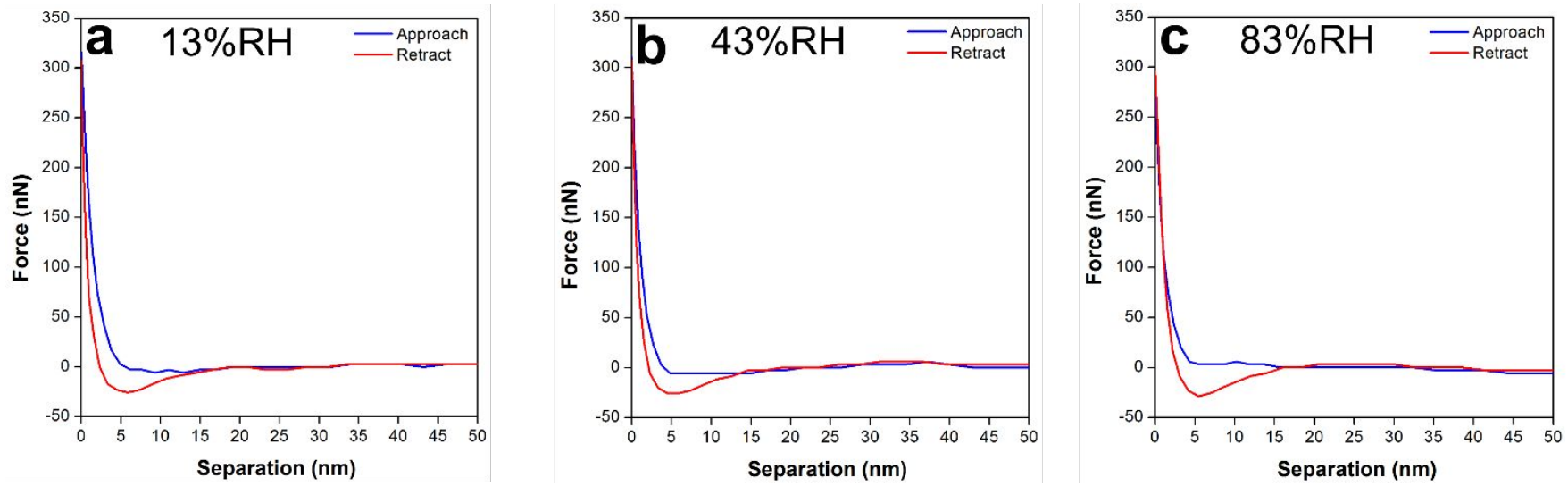

Figure S2. AFM PF-QNM force curves from hemp sclerenchyma G layer at (a) $13 \%$ RH, (b) $43 \%$ RH and (c) $83 \%$ RH. 